\title{
Clinicopathological Features and Outcomes of Gastrointestinal Stromal Tumours in Oman A multi-centre study
}

"Zainab Al-Maqrashi, ${ }^{1}$ Ikram A. Burney, ${ }^{2}$ Kadhim M. Taqi, ${ }^{3}$ Yaqoob Al-Sawafi, ${ }^{4}$ Asim Qureshi, ${ }^{5,6}$ Ritu Lakhtakia, Itrat Mehdi, ${ }^{8}$ Bassim Al-Bahrani, ${ }^{8}$ Shiyam Kumar, ${ }^{9}$ Mansour Al-Moundhri ${ }^{2}$

\begin{abstract}
Objectives: This study aimed to report the clinicopathological features, management and long-term outcomes of patients with gastrointestinal stromal tumours (GISTs) in Oman. Methods: This retrospective study was conducted on patients treated for GIST between January 2003 and December 2017 at three tertiary referral centres in Muscat, Oman. All patients with confirmed histopathological diagnoses of GIST and followed-up at the centres during this period were included. Relevant information was retrieved from hospital records until April 2019. Results: A total of 44 patients were included in the study. The median age was 55.5 years and $56.8 \%$ were female. The most common primary site of disease was the stomach (63.6\%) followed by the jejunum/ileum (18.2\%). Two patients (4.5\%) had c-Kit-negative, discovered on GIST-1-positive disease. A total of 24 patients (54.5\%) presented with localised disease and eight (33.3\%) were classified as being at high risk of relapse. Patients with metastatic disease received imatinib in a palliative setting, whereas those with completely resected disease in the intermediate and high-risk groups were treated with adjuvant imatinib. Of the six patients (13.6\%) with progressive metastatic disease, of which four had mutations on exon 11 and one on exon 9, while one had wild-type disease. Overall, rates of progression-free survival and overall survival (OS) at 100 months were $77.4 \%$ and $80.4 \%$, respectively. Rates of OS for patients with localised and metastatic disease were $89.9 \%$ and $80.2 \%$, respectively. Conclusion: The presenting features and outcomes of patients with GISTs in Oman were comparable to those reported in the regional and international literature.
\end{abstract}

Keywords: Gastrointestinal Stromal Tumors; Proto-Oncogene Proteins c-kit; Protein Kinase Inhibitors; Imatinib; Adjuvant Chemotherapy; Survival Rate; Oman.

\section{Advances IN KNOWLEDGe \\ Survival data from the current study were comparable with previous findings published in regional and international literature. \\ To the best of the authors' knowledge, this is the first study to report the long-term outcomes of patients with gastrointestinal stromal tumours (GISTS) in the Middle East and may serve as a benchmark for future studies.}

\section{Application to Patient Care}

Results from this study support the use of international GIST treatment protocols in the local setting of Oman.

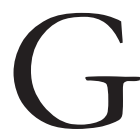
ASTROINTESTINAL STROMAL TUMOURS (GISTs) are the most common mesenchymal tumours of the gastrointestinal tract (GIT), yet account for only $2 \%$ of all GIT cancers. ${ }^{1}$ While GISTs can arise from any part of the GIT, the most commonly affected sites are the stomach (60\%) and small intestine (30\%); however, GISTs can also arise from other intra-abdominal sites including the mesentery and omentum. ${ }^{2,3}$ Although a diagnosis of a GIST can be indicated based on histological features, it is established via the immunohistochemical expression of either the cluster of differentiation (CD)117 protein coding for the $c$-Kit gene or the discovered on GIST1 (DOG-1) protein.,5 Overall, CD117 is expressed in approximately 90-95\% of cases, although such patients may harbour mutations on different exons. ${ }^{4}$
Patients with GISTs without CD117 expression may harbour mutations in the platelet-derived growth factor receptor- $\alpha$ (PDGFR- $\alpha$ ) gene or may have wildtype tumours with substantial reductions in the expression of succinate dehydrogenase. ${ }^{6}$

Complete surgical resection is the mainstay of treatment for GIST cases with localised disease. ${ }^{4}$ More recently, it has become possible to stratify patients based on risk of recurrence into various categories using either the National Institutes of Health (NIH), Armed Forces Institute of Pathology (AFIP) or modified Jonessu criteria., ${ }^{4,7}$ In general, the risk of relapse depends on the site and size of the tumour and its mitotic rate..$^{8-10}$ In particular, metastatic GISTs are resistant to standard chemotherapy. ${ }^{11}$ The introduction of tyrosine kinase inhibitors (TKIs)

${ }^{1}$ Department of Medicine, McMaster University, Hamilton, Canada; ${ }^{2}$ Department of Medicine, College of Medicine E Health Sciences, Sultan Qaboos University, Muscat, Oman; ${ }^{3}$ Division of General Surgery, Department of Surgery, Faculty of Medicine, University of British Columbia, Vancouver, Canada; ${ }^{4}$ Department of General Surgery, Armed Forces Hospital, Muscat, Oman; ${ }^{5}$ Department of Pathology, King's Mill Hospital, Sherwood Forest Hospitals National Health Service Foundation Trust, Mansfield, Nottinghamshire, UK; ${ }^{6}$ Department of Pathology, Sultan Qaboos University Hospital, Muscat, Oman; ${ }^{7}$ Department of Pathology, Mohammed bin Rashid University of Medicine \& Health Sciences, Dubai, United Arab Emirates; ${ }^{8}$ National Oncology Centre, Royal Hospital, Muscat, Oman; ${ }^{9}$ Department of Medical Oncology, Yeovil District Hospital NHS Foundation Trust, Somerset, UK

*Corresponding Author's e-mail: zmaqrashi@gmail.com 
has not only dramatically improved the prognosis of patients with unresectable, recurrent or metastatic GISTs, but also reduced the risk of recurrence and improved progression-free survival (PFS) and overall survival (OS) rates in patients considered to have a high risk of relapse after complete resection. ${ }^{12}$

Nevertheless, while several studies have sought to report the presentation and outcomes of GIST cases across the world, there remains a scarcity of literature from Oman and the Gulf region. ${ }^{13-16}$ As such, this study aimed to report the clinicopathological features and outcomes of GIST cases in Oman.

\section{Methods}

This retrospective multicentre study was conducted between January 2003 and December 2017 at the Sultan Qaboos University Hospital, Armed Forces Hospital and Royal Hospital in Muscat, Oman. These three major tertiary hospitals receive referrals from all over the country for the evaluation and management of cancer cases. All patients diagnosed with histopathologically-confirmed GISTs during the study period at these hospitals and with complete followup data were included. Patients with incomplete data, including patients who were lost to follow-up, those diagnosed elsewhere and those for whom a major part of treatment was carried out at other hospitals were excluded.

The patients' clinical and sociodemographic data were collected from paper and electronic hospital records. In addition, other information was recorded, including primary tumour site, metastatic sites, histopathological subtype and immunohistochemical patterns of expression of relevant diagnostic markers, as well as type of surgery employed, use of TKIs and indications for treatment with imatinib (i.e. in an adjuvant, neoadjuvant or palliative setting). For cases in which the tumour was completely resected, risk of relapse was determined using the AFIP-Miettinen criteria incorporating tumour size, mitotic rate and site as prognostic factors. ${ }^{7}$ Subsequently, the NIH criteria was utilised for the purposes of comparative stratification with regional data, with patients subcategorised into four risk groups based on tumour size and mitotic activity. ${ }^{4}$

Kaplan-Meier curves were used to estimate survival rates, with OS calculated from the date of diagnosis to the date of death or last follow-up. The data cut-off point was the end of April 2019. A logrank test was used for the purposes of comparative analysis. This study was approved by the individual institutional ethical committees of all three hospitals.

\section{Results}

Over the 15-year study period, a total of 44 patients were diagnosed with GISTs and treated at the three referral centres. Of these, 19 (43.2\%) were male and 25 (56.8\%) were female. The median age at diagnosis was 55.5 years (range: $26-83$ years). The majority of patients presented with abdominal pain $(81.8 \%$; $\mathrm{n}=36)$, GIT bleeding $(47.7 \% ; \mathrm{n}=21)$ or constitutional symptoms $(29.5 \% ; n=13)$ such as fever, weakness and weight loss. The most common primary site of the tumour was the stomach $(63.6 \%)$ followed by the jejunum/ileum

Table 1: Clinicopathological characteristics of patients diagnosed with gastrointestinal stromal tumours over a 15-year period at three tertiary referral centres in Muscat, Oman $(\mathrm{N}=44)$

\begin{tabular}{|c|c|}
\hline Characteristic & n (\%) \\
\hline \multicolumn{2}{|l|}{ Gender } \\
\hline Male & $19(43.2)$ \\
\hline Female & $25(56.8)$ \\
\hline \multicolumn{2}{|l|}{ Age in years } \\
\hline Mean \pm SD & $55.5 \pm 13.1$ \\
\hline Range & $26-83$ \\
\hline \multicolumn{2}{|l|}{ Site of primary tumour } \\
\hline Stomach & $28(63.6)$ \\
\hline Jejunum/ileum & $8(18.2)$ \\
\hline Duodenum & $4(9.1)$ \\
\hline Rectum & $3(6.8)$ \\
\hline Extraintestinal & $1(2.3)$ \\
\hline \multicolumn{2}{|l|}{ Histological subtype } \\
\hline Spindle cell & $26(59.1)$ \\
\hline Epithelioid & $2(4.5)$ \\
\hline Mixed & $16(36.4)$ \\
\hline \multicolumn{2}{|l|}{ Disease extension } \\
\hline Localised & $24(54.5)$ \\
\hline Metastatic & $20(45.5)$ \\
\hline \multicolumn{2}{|l|}{ Risk category* } \\
\hline None & $2(8.3)$ \\
\hline Very low & $4(16.7)$ \\
\hline Low & $5(20.8)$ \\
\hline Moderate (Intermediate) & $4(16.7)$ \\
\hline High & $8(33.3)$ \\
\hline Unknown & $1(4.2)$ \\
\hline
\end{tabular}


Table 2: Management of patients diagnosed with gastrointestinal stromal tumours and treated surgically over a 15-year period at three tertiary referral centres in Muscat, Oman $(\mathrm{N}=34)$

\begin{tabular}{|c|c|c|}
\hline \multirow{2}{*}{$\begin{array}{l}\text { Primary site of tumour/ } \\
\text { type of surgery }\end{array}$} & \multicolumn{2}{|c|}{ Disease extension, $\mathbf{n}(\%)$} \\
\hline & $\begin{array}{l}\text { Localised* } \\
\quad(\mathrm{n}=24)\end{array}$ & $\begin{array}{c}\text { Metastatic }^{\dagger} \\
(\mathbf{n}=10)\end{array}$ \\
\hline \multicolumn{3}{|l|}{ Upper GIT } \\
\hline Wedge resection/excision & $11(45.8)$ & $2(20)$ \\
\hline Partial gastrectomy & $3(12.5)$ & $0(0)$ \\
\hline Subtotal/total gastrectomy & $3(12.5)$ & $2(20)$ \\
\hline \multicolumn{3}{|l|}{ Small intestine } \\
\hline Resection and anastomosis & $5(20.8)$ & $3(30)$ \\
\hline \multicolumn{3}{|l|}{ Rectum } \\
\hline Hartman's procedure & $0(0)$ & $2(20)$ \\
\hline Abdominoperineal resection & $0(0)$ & $1(10)$ \\
\hline $\begin{array}{l}\text { Multivisceral Resection } \\
\text { (Gastric: distal gastrectomy } \\
\text { with cholecystectomy and } \\
\text { gastrojejunostomy; Duodenal: } \\
\text { Whipple's procedure) }\end{array}$ & $2(8.3)$ & $0(0)$ \\
\hline
\end{tabular}

(18.2\%). One patient (2.3\%) had an extraintestinal GIST. In addition, one patient had underlying neurofibromatosis type I, while another had concomitant colon cancer. Overall, 24 (54.5\%) and 20 (45.5\%) patients presented with localised and metastatic disease, respectively [Table 1].
The majority of tumours were of the spindle cell type $(59.1 \% ; n=26)$. Tumours ranged in size from 2-29 cm, with 29 patients (65.9\%) having tumours of $>5 \mathrm{~cm}$ in its greatest dimension. A total of 42 patients (95.5\%) had CD117-immunoreactive disease. The remaining two cases $(4.5 \%)$ were negative for CD117 but positive for DOG-1. The most common sites of metastases were the liver ( $\mathrm{n}=18 ; 90 \%$ ), peritoneum ( $\mathrm{n}=7 ; 35 \%)$, lungs $(\mathrm{n}=4 ; 20 \%)$ and skeleton $(\mathrm{n}=2$; $10 \%)$. Out of the 20 patients diagnosed with metastatic disease, six (30\%) had progressive disease; of these, four had mutations on exon 11 and one on exon 9. The remaining patients had underlying neurofibromatosis and was diagnosed with wild-type disease.

Of the patients who presented with localised disease, two (8.3\%) received neoadjuvant imatinib and both responded to the treatment, subsequently allowing for wedge resection of the stomach. A total of 14 patients (58.3\%) received adjuvant imatinib according to the guidelines, whereas eight (33.3\%) were diagnosed before 2009 and treated using an expectant approach. Among the patients presenting with metastatic disease, all but one (95\%) received palliative treatment using imatinib. The only patient who did not receive imatinib presented with a score of 4 on the Eastern Cooperative Oncology Group/World Health Organization Performance Status scale and died within a week of diagnosis. ${ }^{17}$
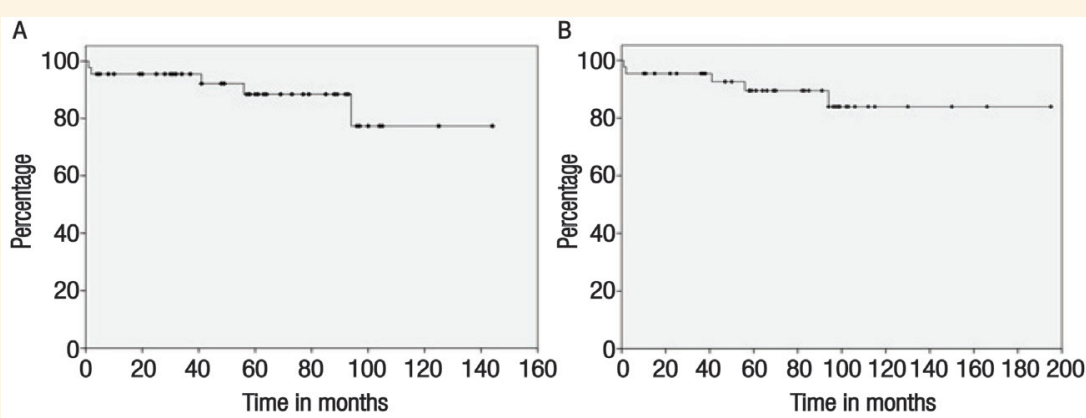

Figure 1: Kaplan-Meier curves showing (A) progression-free survival and (B) overall survival among patients diagnosed with gastrointestinal stromal tumours over a 15-year period at three tertiary referral centres in Muscat, Oman $(\mathrm{N}=44)$.
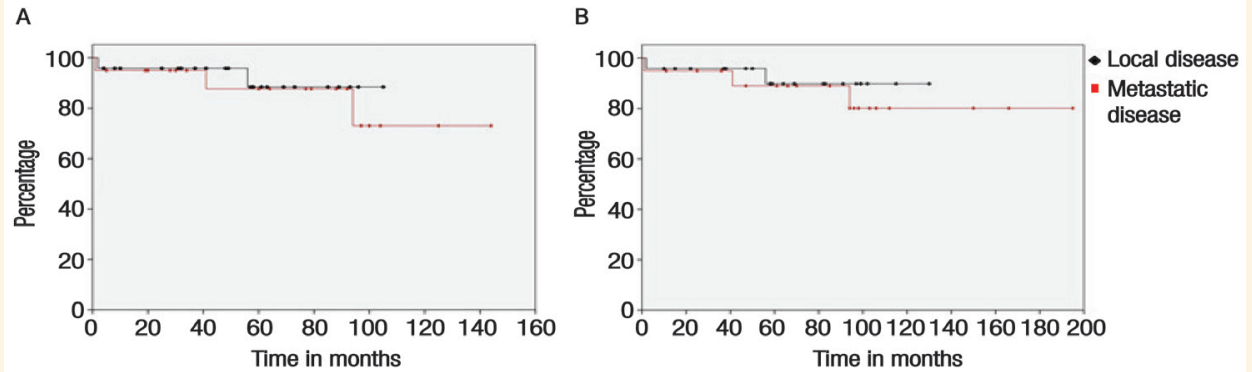

Figure 2: Kaplan-Meier curves showing (A) progression-free survival and (B) overall survival according to disease extension among patients diagnosed with gastrointestinal stromal tumours over a 15-year period at three tertiary referral centres in Muscat, Oman $(\mathrm{N}=44)$. 


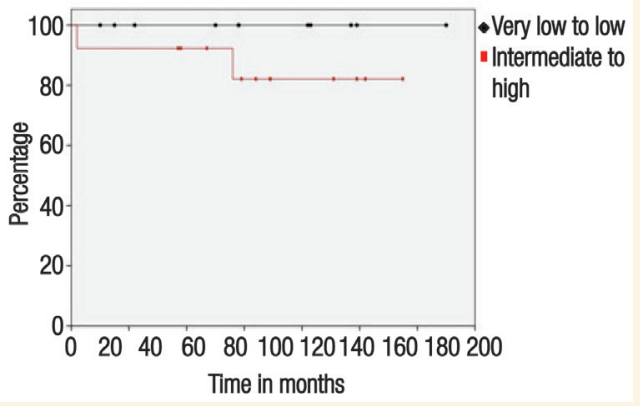

Figure 3: Kaplan-Meier curve showing overall survival according to risk category* among patients diagnosed with gastrointestinal stromal tumours over a 15-year period at three tertiary referral centres in Muscat, Oman $(\mathrm{N}=44)$.

"Risk stratification was performed using the Armed Forces Institute of Pathology-Miettinen criteria.

Out of the 19 patients treated with imatinib, 11 (57.9\%) were still being treated at the time of the data cut-off point and eight (42.1\%) relapsed after a mean of 55 months and were switched to second-line treatment with either high doses of imatinib $(n=4 ; 50 \%)$ or sunitinib $(n=4 ; 50 \%)$. In addition to palliative systemic treatment, 10 metastatic patients (50\%) underwent palliative surgical resection of the primary tumour site due to either bleeding or obstruction [Table 2].

Overall, the 100-month PFS and OS rates were $77.4 \%$ and $80.4 \%$, respectively [Figure 1]. For patients with localised and metastatic disease, OS rates were $89.9 \%$ and $80.2 \%$, respectively [Figure 2]. Among patients with localised disease, the OS rate for those with very low or low risk of relapse was $100 \%$, dropping to $81 \%$ for those at intermediate or high risk [Figure 3].

\section{Discussion}

To the best of the authors' knowledge, this is the first study to report the long-term outcomes of GIST cases in Oman. In total, 44 patients were diagnosed with GISTs and followed-up over a 15-year period at the three main tertiary referral centres in Oman. This likely constitutes the vast majority of national GIST cases during this period, given that these centres receive cancer referrals from all over the country. Overall, 24 patients presented with localised disease and underwent complete resection, followed by adjuvant treatment according to institutional guidelines, while 19 patients who presented with metastatic disease

Table 3: Studies assessing overall survival and risk of relapse among patients with gastrointestinal stromal tumours ${ }^{13-16,18-22}$

\begin{tabular}{|c|c|c|c|c|c|c|c|c|c|}
\hline \multirow{2}{*}{$\begin{array}{l}\text { Author } \\
\text { and year of } \\
\text { publication }\end{array}$} & \multirow[t]{2}{*}{ Country } & \multirow{2}{*}{$\begin{array}{c}\text { Sample } \\
\text { size }\end{array}$} & \multirow{2}{*}{$\begin{array}{c}\text { Metastatic at } \\
\text { presentation, } \\
\text { n (\%) }\end{array}$} & \multirow{2}{*}{$\begin{array}{l}\text { Mean age } \\
\text { in years } \pm \\
S D \text { (range) }\end{array}$} & \multicolumn{4}{|c|}{ Risk of relapse ${ }^{*}, \mathbf{n}(\%)$} & \multirow{2}{*}{$\begin{array}{c}\text { OS rate } \\
\text { in \% } \\
\text { (period) }\end{array}$} \\
\hline & & & & & Very low & Low & Intermediate & High & \\
\hline $\begin{array}{l}\text { Makar et al. } .^{13} \\
(2002)\end{array}$ & Kuwait & $26^{\dagger}$ & - & $\begin{array}{c}54.0 \pm 12.2 \\
(25-80)\end{array}$ & $2(9.5)^{\ddagger}$ & $6(28.6)^{\ddagger}$ & $2(9.5)^{\ddagger}$ & $11(52.4)^{\ddagger}$ & - \\
\hline $\begin{array}{l}\text { Barakat et } \\
\text { al. }^{14}(2010)\end{array}$ & Jordan & 42 & $3(7.1)$ & 53 & $2(5.1)$ & $6(15.4)$ & $4 \cdot(10.3)$ & $27(69.2)$ & - \\
\hline $\begin{array}{l}\text { Al Hussaini }{ }^{15} \\
\text { (2012) }\end{array}$ & $\begin{array}{l}\text { Saudi } \\
\text { Arabia }\end{array}$ & 75 & - & $\begin{array}{l}56.5 \pm 16.95 \\
\quad(8-90)\end{array}$ & $12(16)$ & $25(33.3)$ & $17(22.7)$ & $21(28)$ & - \\
\hline $\begin{array}{l}\text { Al-Thani } e t \\
\text { al. }{ }^{16}(2014)\end{array}$ & Qatar & 48 & - & $48.4 \pm 13.7$ & $0(0)$ & $0(0)$ & $18(37.5)$ & $9(18.8)$ & 43.8 \\
\hline $\begin{array}{l}\text { Yacob et al. } .^{18} \\
(2015)\end{array}$ & India & 150 & - & $(19-79)$ & $73(48.6)^{\S}$ & $35(23.3)$ & $42(28)$ & $\begin{array}{c}86.6 \% \\
\text { (Three-year } \\
\text { rate) }\end{array}$ & \\
\hline $\begin{array}{l}\text { Ud Din et } \\
\text { al. }{ }^{19}(2015)\end{array}$ & Pakistan & $255^{\prime}$ & - & $51(16-83)$ & $3(1.4)^{/ /}$ & $24(10.9)^{/ /}$ & $39(17.7)^{/ /}$ & $154(70)^{/ /}$ & - \\
\hline $\begin{array}{l}\text { Salem et al. }{ }^{20} \\
(2016)\end{array}$ & Egypt & 36 & 14. (28.9) & $\begin{array}{l}52.8 \pm 14.4 \\
(17-76)\end{array}$ & $1(2.8)^{* * *}$ & $4(11.1)^{* * *}$ & $11(30.6)^{* * *}$ & $18(50.6)^{* *}$ & $\begin{array}{l}51 \text { (Five- } \\
\text { year } \\
\text { rate) }\end{array}$ \\
\hline $\begin{array}{l}\text { McDonnell } \\
\text { et al. }{ }^{21}(2017)\end{array}$ & UK & 42 & - & $68(43-91)$ & $2(8)$ & $7(28)$ & $4 \cdot(16)$ & $12(48)$ & - \\
\hline $\begin{array}{l}\text { Cavaliere et } \\
\text { al. }{ }^{22}(2005)\end{array}$ & Italy & 22 & $2(9.1)$ & $\begin{array}{l}67 \pm 10 \\
(47-86)\end{array}$ & $1(5)$ & $9(45)$ & $3(15)$ & $7(35)$ & $\begin{array}{l}78.9 \\
\text { (Five- } \\
\text { year } \\
\text { rate) }\end{array}$ \\
\hline $\begin{array}{l}\text { Present study } \\
(2021)\end{array}$ & Oman & 44 & $20(45.5)$ & $\begin{array}{l}54.2 \pm 13.1 \\
(26-83)\end{array}$ & $2(8.4)$ & $5(20.8)$ & $6(25)$ & $11(45.8)$ & $\begin{array}{l}80.4 \\
(100- \\
\text { month } \\
\text { rate })\end{array}$ \\
\hline
\end{tabular}


received imatinib. A comparative analysis of regional and international research concerning GIST cases is presented in Table $3 .{ }^{13-16,18-22}$

In the current study, the median age at presentation was 55.5 years. While this finding is consistent with other studies published from countries in South East Asia and the Middle East, it varies compared to studies from the UK and Italy. ${ }^{13-16,18-22}$ This could be explained by either methodological differences in patient selection or may be reflective of the average age of the local population; however, this remains speculative. The stomach was the primary site of involvement in almost two-thirds of patients in the present study. Similarly, Miettinen et al. reported the stomach to be the most common primary site (60\%) followed by the jejunum and ileum (30\%), duodenum (5\%) and colorectum (5\%), while Dematteo et al. reported involvement of the stomach, small intestine and rectum in $50 \%, 42 \%$ and $1 \%$ of GIST cases, respectively. ${ }^{2,9}$

The biological behaviour of resected GISTs are a particular focus of interest worldwide. Moreover, with the emergence of risk stratification systems, predictions regarding a patient's prognosis have become more reliable. Initially, tumour size and mitotic figures were used to categorise GIST patients into subgroups in terms of risk of relapse; the $\mathrm{NIH}$ consensus criteria, also known as Fletcher's criteria, uses both parameters to stratify patients into very low, low, intermediate and high-risk groups. ${ }^{4}$ Dematteo et al. suggested that location of the primary tumour be added as an independent factor; however, this has not yet been included in the $\mathrm{NIH}$ criteria. ${ }^{9}$ In contrast, the AFIP criteria, also known as Miettinen's criteria, incorporates this as a prognostic factor. ${ }^{7}$ Patients are categorised into four groups based on tumour size and two groups with regards to mitotic count, while primary tumours are classified into either stomach, duodenum, ileum/jejunum or rectum tumours. ${ }^{10}$

In 2008, Joensuu revised the NIH criteria and proposed the inclusion of both tumour site and rupture as high-risk factors. ${ }^{8}$ Several other modifications have been suggested-such as peritoneal dissemination, metastasis and invasion and the mutation status of the $c$-Kit and PDGFR- $\alpha$ genes - as risk stratification criteria continue to evolve. ${ }^{23}$ In addition, two nomograms have been proposed for the purposes of risk assessment. ${ }^{24,25}$ In the current study, as data regarding tumour rupture were not available for all patients, the AFIP-Miettinen criteria were used to categorise patients into risk categories. ${ }^{7}$ Nonetheless, according to $\mathrm{NIH}$ scoring system, among patients with localised disease, seven (29.2\%) were at very low to low risk, six (25\%) were at intermediate risk and $11(45.8 \%)$ were at high risk of relapse [Table 3].
These observations compare favourably with reports from the UK, Qatar, Kuwait, Jordan, Egypt and Pakistan, but are at variance with reports from Saudi Arabia and India. ${ }^{13-16,18-21}$ This discrepancy could be attributed to variations in patient populations, referral patterns or the risk criteria being used.

Imatinib was approved for use in CD117expressing metastatic GISTs in 2002; however, the drug was only approved in intermediate-to-high-risk cases in an adjuvant setting in 2008. ${ }^{26}$ Subsequently, in 2012, a confirmatory phase III trial suggested that patients taking imatinib for 36 months in an adjuvant setting had better five-year OS rates compared to those who took the drug for one year ( $92 \%$ versus $82 \%$ ); furthermore, three-year treatment resulted in a $54 \%$ reduction in recurrence and a 55\% reduction in risk of death compared to one-year treatment. ${ }^{27}$ Almost all patients with metastatic disease in the present cohort were treated with imatinib; however, patients with completely resected GISTs did not receive imatinib in an adjuvant setting until 2008. One patient received treatment for 12 months according to available data at the time, with the rest treated for three years according to more recent clinical practice guidelines. ${ }^{28}$

In the current study, all patients initially received $400 \mathrm{mg}$ of imatinib. According to previous research, there is no difference in survival between patients treated with $400 \mathrm{mg}$ of imatinib compared to $800 \mathrm{mg}$, except in a subset of patients with exon 9 mutations on the $c$-Kit gene. ${ }^{29}$ According to recent clinical practice guidelines, $800 \mathrm{mg}$ of imatinib is recommended for patients with metastatic and inoperable disease including those with exon 9 mutations.$^{28}$ In the present cohort, exon 9 mutations were only identified in a single case. This patient was subsequently treated with $800 \mathrm{mg}$ of imatinib, tolerated the escalated dose and has been in stable remission for the last five years as of the time of writing. Following mutational analysis, all four patients with exon 11 mutations were treated with sunitinib and regorafenib as second- and thirdline treatments, respectively.

In the current study, the 100-month PFS rate was $77.4 \%$, whereas the OS rate was $80.4 \%$, signifying that $>80 \%$ of patients were alive and free of disease after eight years. Overall, $89.9 \%$ of those with localised disease survived, as did $80.2 \%$ of those who presented with metastatic disease. In terms of risk of relapse, 100 -month OS rates were $100 \%$ for very low to low risk of relapse patients' group and $81 \%$ for those at intermediate to high risk, $100 \%$ and $80 \%$ for patients in low, intermediate or high-risk categories, respectively. In a cohort of 124 GIST patients, of which $47 \%$ were high-risk cases, Mucciarini et al. reported five-year disease-free survival rates of 94\%, 92\%, 100\% and 40\% 
for patients at very low, low, intermediate and high risk, respectively. ${ }^{30}$ According to findings from a large intergroup trial, Casali et al. reported a median PFS and OS duration of 1.7 and 3.9 years, respectively, among 472 patients treated with $400 \mathrm{mg}$ of imatinib daily for metastatic or locally advanced disease. ${ }^{12}$

Although the current study had multiple strengths-such as the involvement of multiple tertiary cancer referral centres, a lengthy follow-up duration of 15 years and the inclusion of almost all GIST patients in Oman-it was also subject to several limitations. Due to the retrospective nature of the study, certain information was not available including the incidence of tumour rupture or bleeding. However, international risk stratification criteria were used, incorporating recognised prognostic factors such as tumour site, size and mitotic count. Furthermore, mutational analysis was only performed for those in whom the disease progressed in order to guide subsequent treatment; nevertheless, this is not currently indicated for patients receiving adjuvant imatinib, as it does not affect survival. ${ }^{31}$

\section{Conclusion}

This study reported the outcomes of localised and metastatic GIST cases presenting to three tertiary referral centres in Oman over a 15-year period, as well as clinical presentations, risk categories for relapse and PFS and OS rates. The presenting features and outcomes of patients with GISTs in Oman were comparable to those reported in the regional and international literature. To the best of the authors' knowledge, this is the first study to report the longterm outcomes of patients with GISTs from the Middle East and may serve as a benchmark for future studies.

\section{CONFLICT OF INTEREST}

The authors declare no conflicts of interest.

\section{FUNDING}

No funding was received for this study.

\section{References}

1. Miettinen M, Sarlomo-Rikala M, Lasota J. Gastrointestinal stromal tumors: Recent advances in understanding of their biology. Hum Pathol 1999; 30:1213-20. https://doi.org/10.1016/ s0046-8177(99)90040-0.

2. Miettinen M, Lasota J. Gastrointestinal stromal tumors: Pathology and prognosis at different sites. Semin Diagn Pathol 2006; 23:70-83. https://doi.org/10.1053/j.semdp.2006.09.001.
3. Miettinen M, Lasota J. Gastrointestinal stromal tumors: Review on morphology, molecular pathology, prognosis, and differential diagnosis. Arch Pathol Lab Med 2006; 130:1466-78. https:// doi.org/10.5858/2006-130-1466-GSTROM.

4. Fletcher CD, Berman JJ, Corless C, Gorstein F, Lasota J, Longley BJ, et al. Diagnosis of gastrointestinal stromal tumors: A consensus approach. Hum Pathol 2002; 33:459-65. https:// doi.org/10.1053/hupa.2002.123545.

5. West RB, Corless CL, Chen X, Rubin BP, Subramanian S, Montgomery $\mathrm{K}$, et al. The novel marker, DOG1, is expressed ubiquitously in gastrointestinal stromal tumors irrespective of KIT or PDGFRA mutation status. Am J Pathol 2004; 165:107-13. https://doi.org/10.1016/S0002-9440(10)63279-8.

6. Janeway KA, Kim SY, Lodish M, Nosé V, Rustin P, Gaal J, et al. Defects in succinate dehydrogenase in gastrointestinal stromal tumors lacking KIT and PDGFRA mutations. Proc Natl Acad Sci U S A 2011; 108:314-18. https://doi.org/10.1073/pnas.10 09199108.

7. Miettinen M, Sobin LH, Lasota J. Gastrointestinal stromal tumors of the stomach: A clinicopathologic, immunohistochemical, and molecular genetic study of 1765 cases with longterm follow-up. Am J Surg Pathol 2005; 29:52-68. https://doi. org/10.1097/01.pas.0000146010.92933.de.

8. Joensuu H. Risk stratification of patients diagnosed with gastrointestinal stromal tumor. Hum Pathol 2008; 39:1411-19. https://doi.org/10.1016/j.humpath.2008.06.025.

9. Dematteo RP, Gold JS, Saran L, Gönen M, Liau KH, Maki RG, et al. Tumor mitotic rate, size, and location independently predict recurrence after resection of primary gastrointestinal stromal tumor (GIST). Cancer 2008; 112:608-15. https://doi. org/10.1002/cncr.23199.

10. Rutkowski P, Nowecki ZI, Michej W, Debiec-Rychter M, Woźniak A, Limon J, et al. Risk criteria and prognostic factors for predicting recurrences after resection of primary gastrointestinal stromal tumor. Ann Surg Oncol 2007; 14:2018-27. https://doi.org/10.1 245/s10434-007-9377-9.

11. Joensuu H, Fletcher C, Dimitrijevic S, Silberman S, Roberts P, Demetri G. Management of malignant gastrointestinal stromal tumours. Lancet Oncol 2002; 3:655-64. https://doi.org/https:// doi.org/10.1016/S1470-2045(02)00899-9.

12. Casali PG, Zalcberg J, Le Cesne A, Reichardt P, Blay JY, Lindner LH, et al. Ten-year progression-free and overall survival in patients with unresectable or metastatic GI stromal tumors: Long-term analysis of the European Organisation for Research and Treatment of Cancer, Italian Sarcoma Group, and Australasian Gastrointestinal Trials Group intergroup phase III randomized trial on imatinib at two dose levels. J Clin Oncol 2017; 35:1713-20. https://doi.org/10.1200/JCO.2016.71.0228.

13. Makar RR, al-Waheeb S, John B, Junaid TA. Gastrointestinal stromal tumors: Clinicopathological and immunohistochemical features. Med Princ Pract 2002; 11:93-9. https://doi.org/10.11 59/000058014.

14. Barakat FH, Haddad HA, Matalka II, Al-Orjani MS, Al-Masri MM, Sughayer MA. Characteristics of gastrointestinal stromal tumors in a Middle Eastern population. Saudi Med J 2010; 31:797-802.

15. Al Hussaini HF. GIST in Saudi Arabia: Multicentric histopathological genetic study of 75 surgically excised cases. Gulf J Oncolog 2012; 11:31-7.

16. Al-Thani H, El-Menyar A, Rasul KI, Al-Sulaiti M, El-Mabrok J, Hajaji $\mathrm{K}$, et al. Clinical presentation, management and outcomes of gastrointestinal stromal tumors. Int J Surg 2014; 12:1127-33. https://doi.org/10.1016/j.ijsu.2014.08.351.

17. Oken MM, Creech RH, Tormey DC, Horton J, Davis TE, McFadden ET, et al. Toxicity and response criteria of the Eastern Cooperative Oncology Group. Am J Clin Oncol 1982; 5:649-55. https://doi.org/10.1097/00000421-198212000-00014. 
18. Yacob M, Inian S, Sudhakar CB. Gastrointestinal stromal tumours: Review of 150 cases from a single centre. Indian I Surg 2015; 77:505-10. https://doi.org/10.1007/s12262-013-0899-z.

19. Ud Din N, Ahmad Z, Arshad H, Idrees R, Kayani N. Gastrointestinal stromal tumors: A clinicopathologic and risk stratification study of 255 cases from Pakistan and review of literature. Asian Pac J Cancer Prev 2015; 16:4873-80. https:// doi.org/10.7314/apjcp.2015.16.12.4873.

20. Salem AAS, Elshoieby MH, Maximos DW, El-Saba TM. Gastrointestinal stromal tumors (GISTs), surgical management and clinical outcome. J Cancer Ther 2016; 7:319-28. https:// doi.org/10.4236/jct.2016.74034.

21. McDonnell MJ, Punnoose S, Viswanath YKS, Wadd NJ, Dhar A. Gastrointestinal stromal tumours (GISTs): An insight into clinical practice with review of literature. Frontline Gastroenterol 2017; 8:19-25. https://doi.org/10.1136/flgastro-2015-100670.

22. Cavaliere D, Griseri G, Venturino E, Schirru A, Cosce U, Caristo I et al. Management of patients with gastrointestinal stromal tumors: Experience from an Italian hospital. Tumori 2005; 91:467-71. https://doi.org/10.1177/030089160509100604.

23. Takahashi T, Nakajima K, Nishitani A, Souma Y, Hirota S, Sawa Y, et al. An enhanced risk-group stratification system for more practical prognostication of clinically malignant gastrointestinal stromal tumors. Int J Clin Oncol 2007; 12:369-74. https://doi. org/10.1007/s10147-007-0705-7.

24. Gold IS, Gönen M, Gutiérrez A, Broto JM, García-del-Muro X, Smyrk TC, et al. Development and validation of a prognostic nomogram for recurrence-free survival after complete surgical resection of localised primary gastrointestinal stromal tumour: A retrospective analysis. Lancet Oncol 2009; 10:1045-52. https://doi.org/10.1016/S1470-2045(09)70242-6.
25. Rossi S, Miceli R, Messerini L, Bearzi I, Mazzoleni G, Capella C, et al. Natural history of imatinib-naive GISTs: A retrospective analysis of 929 cases with long-term follow-up and development of a survival nomogram based on mitotic index and size as continuous variables. Am J Surg Pathol 2011; 35:1646-56. https://doi.org/10.1097/PAS.0b013e31822d63a7.

26. Demetri GD, von Mehren $M$, Blanke CD, Van den Abbeele AD, Eisenberg B, Roberts PJ, et al. Efficacy and safety of imatinib mesylate in advanced gastrointestinal stromal tumors. $\mathrm{N}$ Engl J Med 2002; 347:472-80. https://doi.org/10.1056/NEJMoa020461.

27. Joensuu H, Eriksson M, Sundby Hall K, Hartmann JT, Pink D, Schütte J, et al. One vs three years of adjuvant imatinib for operable gastrointestinal stromal tumor: A randomized trial. JAMA 2012; 307:1265-72. https://doi.org/10.1001/jama.2012.347.

28. Judson I, Bulusu R, Seddon B, Dangoor A, Wong N, Mudan S. UK clinical practice guidelines for the management of gastrointestinal stromal tumours (GIST). Clin Sarcoma Res 2017; 7:6. https://doi.org/10.1186/s13569-017-0072-8.

29. Gastrointestinal Stromal Tumor Meta-Analysis Group (MetaGIST). Comparison of two doses of imatinib for the treatment of unresectable or metastatic gastrointestinal stromal tumors: A meta-analysis of 1,640 patients. J Clin Oncol 2010; 28:1247-53. https://doi.org/10.1200/JCO.2009.24.2099.

30. Mucciarini C, Rossi G, Bertolini F, Valli R, Cirilli C, Rashid I, et al. Incidence and clinicopathologic features of gastrointestinal stromal tumors: A population-based study. BMC Cancer 2007; 7:230. https://doi.org/10.1186/1471-2407-7-230.

31. Corless CL, Ballman KV, Antonescu CR, Kolesnikova V Maki RG, Pisters PW, et al. Pathologic and molecular features correlate with long-term outcome after adjuvant therapy of resected primary GI stromal tumor: The ACOSOG Z9001 trial. J Clin Oncol 2014; 32:1563-70. https://doi.org/10.1200/ JCO.2013.51.2046 